\title{
THERMOGRAVIMETRIC STUDIES OF NASAL GEL WITH DRY EXTRACT OF LICORICE ROOT AND ESSENTIAL OILS
}

\author{
RUKHMAKOVA OLGA A*, KARPENKO IRINA A, YARNYKH TATYANA G
}

\author{
Department of Drugs Technology, National University of Pharmacy, Kharkov, Ukraine. Email: rukhmakovaolga@gmail.com
}

Received: 25 January 2018, Revised and Accepted: 19 April 2018

\section{ABSTRACT}

Objectives: The objectives of this study were to conduct thermogravimetric (TG) studies of nasal gel with dry extract of licorice root and essential oils for the treatment of viral rhinitis.

Methods: TG analysis performs on the derivative Q-1000 of the system F. Paulik, I. Paulik, and L. Efdei with platinum-based thermocouple. Then the curves T (temperature changes), TG (changes in weight), DTA (differentiated curve of thermal effects), DTG (differentiated weight change curve) were recorded. As an inert material, the standard is usually aluminum oxide, which should not undergo transformations with the release or absorption of heat in the temperature range under study. The temperature difference of the sample and the standard is determined by the differential thermocouple. The samples were heated in ceramic crucibles from 18 to $500^{\circ} \mathrm{C}$ in the air. The heating rate was $5^{\circ} \mathrm{C}$ in min. The weight of the samples was $50 \mathrm{mg}$.

Results: In analyzing the derivatograms of all samples, it was found that the developed nasal dosage form of natural raw compounds on the base of carbomer gel is a mechanical mixture of active ingredients and excipients since its ingredients do not interact with each other.

The production of nasal gel with dry extract of licorice root and essential oils of Siberian pine and eucalyptus at temperatures taken in the process of carbomer gel (room temperature) does not lead to destruction of the components of investigated dosage form.

Conclusion: The developed nasal dosage form of natural raw compounds on the base of carbomer gel is a mechanical mixture of active ingredients and excipients since its ingredients do not interact with each other. The production of nasal gel with dry extract of licorice root and essential oils of Siberian pine and eucalyptus at temperatures taken in the process of carbomer gel (room temperature) does not lead to the destruction of the components of investigated dosage form.

Keywords: Thermogravimetric studies, Nasal gel, Dry extract of licorice root, Essential oils.

(c) 2018 The Authors. Published by Innovare Academic Sciences Pvt Ltd. This is an open access article under the CC BY license (http://creativecommons. org/licenses/by/4. 0/) DOI: http://dx.doi.org/10.22159/ajpcr.2018.v11i8.24948

\section{INTRODUCTION}

Rhinitis represents a global health problem that affects $10-20 \%$ of the population. Numerous studies of recent years also indicate an increase in the incidence of rhinitis and among children $[1,2]$.

It is known that in $45-60 \%$ of the rhinitis population, a systemic autoimmune disease such as bronchial asthma continues to develop. Often, rhinitis occurs on the background of atopic dermatitis or other allergic diseases, which complicates the course of the process and affects the effectiveness of its therapy. In addition, it should be noted that in the etiology of rhinitis development, viruses play an important role, which lead to changes in the reactivity of the immune system and lead to polyvalent sensitization of the human body as a whole [2,3].

Despite the diversity of existing treatments, it is not always possible to achieve a sustained clinical effect, which is compounded by the complexity of the pathogenesis of rhinitis. The need for combined therapy of this pathology is confirmed by numerous clinical, functional, and morphological studies.

For symptomatic treatment of rhinitis, drops for the nose, intranasal sprays, nasal gels, ointments, creams, and capsules are most commonly used. Among the advantages of nasal gels, first, it is worth noting the prolongation of their action, the presence of moisturizing action on the mucous membrane of the nasal cavity at its dryness, ease of removal from the surface of hands, and clothing, etc. [4-6].
The existing range of medicines in the modern pharmaceutical market of Ukraine offers a very wide range of medicines for symptomatic treatment of rhinitis, but the proportion of nasal gels among them is very low. Natural products are a constant source of potentially active compounds for the treatment of various disorders. There are several hundreds of drugs being designed and developed based on plant secondary metabolites worldwide [7]. That is why at the Drugs Technology Department of the National University of Pharmacy, a new nasal gel based on natural raw materials with antimicrobial and antiviral action (dry extract of licorice root, essential oils of Siberian pine, and eucalyptus) was created.

It is known that one of the main stages of creating new medicines is the development of their production technology [8]. The process of production of gels includes a sufficiently long heat treatment during preparation of the base, introduction of medicinal substances into it and homogenization. This creates the danger of chemical and physical transformations of the active and auxiliary substances that make up the gel, down to their destruction, and changes in pharmacological, physical, and chemical properties $[9,10]$.

The use of thermogravimetric (TG) analysis in pharmaceutical technology makes it possible to study the possibility of chemical interaction of the components of dosage forms over a wide range of temperatures.

The objective of the work - is to conduct TG studies of nasal gel with dry extract of licorice root and essential oils for the treatment of viral rhinitis. 


\section{METHODS}

As active ingredients of the proposed nasal gel, we used dry licorice root extract, essential oils of Siberian pine and eucalyptus. Given their physical and chemical properties, namely solubility, dry licorice root extract was introduced into the gel in the form of an aqueous solution and essential oils in the form of a solution in ethanol (96\%).

As a structure-forming component in the gel base, the gelling agent carbomer (Carbopol) 934P was used. Triethanolamine was used to neutralize the aqueous dispersions of Carbopol.

The gel was prepared at room temperature by mixing the finished gel and the prepared solutions of the active substances.

TG analysis performs on the derivative Q-1000 of the system F. Paulik, I. Paulik, and L. Efdei with platinum-based thermocouple. Then records the curves $\mathrm{T}$ (temperature changes), $\mathrm{TG}$ (changes in weight), differential thermal analysis (DTA) (differentiated curve of thermal effects), differential thermal gravimetric (DTG) (differentiated weight change curve).

One of the main elements of the derivative is analytical scales. On one shoulder of analytical scales is a rigidly fixed porcelain tube, inside, which is platinum thermocouple. A crucible with the test substance puts at the junction of the thermocouple. Near locates the same tube with a differential thermocouple on the junction, of which a crucible with an inert substance standard is put.

Crucibles are covered with quartz covers. During the experiment, the electric oven is lowered and thus the crucible is detected in the middle of the furnace.

A software device controls the heating of the furnace at a speed of 0.5$24^{\circ} / \mathrm{min}$, the maximum operating temperature of the furnace is $1000^{\circ} \mathrm{C}$. On the other side of the shoulder is a screwdriver hanging induction coil, capable of moving in the field of permanent magnets.

When changing the mass of the sample, the screwdriver returns, and the coil changes its position. The voltage induced in the coil is proportional to the speed of change in mass and is brought to the recording device, which records the differential TG curve (DTG). The curve of mass change (TG) is recorded in the same way.

As an inert material, the standard is usually aluminum oxide, which should not undergo transformations with the release or absorption of heat in the temperature range under study. The volumes of the inert matter standard and the test sample should be the same.

The temperature difference of the sample and the standard is determined by the differential thermocouple. It is possible to obtain the curves of the DTA, in which the temperature difference is marked on the ordinate, while the abscissa is the time during which the substances were heated, placing a differential thermocouple in the investigated and the reference substance at their simultaneous heating.

The samples were heated in ceramic crucibles from 18 to $500^{\circ} \mathrm{C}$ in the air. The heating rate was $5^{\circ} \mathrm{C}$ in min. The weight of the samples was $50 \mathrm{mg}$.

\section{RESULTS}

In analyzing the derivatograms of these samples, it was found that essential oils of Siberian pine and eucalyptus to a temperature $\left(50.0 \pm 1.0^{\circ} \mathrm{C}\right)$ are stable, and in the range of temperatures from $53^{\circ} \mathrm{C}$ to $84^{\circ} \mathrm{C}$, their mass losses are in up to $3 \%$, the process of destruction of samples ends at $200^{\circ} \mathrm{C}$.

Dry extract of licorice root is stable to a temperature $\left(37.0 \pm 1.0^{\circ} \mathrm{C}\right)$, a gradual loss in its mass occurs in the temperature range from $37^{\circ} \mathrm{C}$ to $130^{\circ} \mathrm{C}$ (Fig. 1).
The base begins to melt at a temperature $\left(37 \cdot 0 \pm 1 \cdot 0^{\circ} \mathrm{C}\right)$.

The process of decomposition of the gel takes place in two stages (Fig. 2). At the first stage, up to $37^{\circ} \mathrm{C}$, there is no significant loss of moisture in the mass. The second $\left(37-100^{\circ} \mathrm{C}\right)$ stage is characterized by a rapid continuous process of destruction and is accompanied by significant exothermic effects.

Thus, based on conducted TG studies, it was found that the thermal effects of samples have a similar character that can subjectively indicate the absence of chemical interaction between components of the gel.

\section{CONCLUSION}

1. The developed nasal dosage form of natural raw compounds on the base of carbomer gel is a mechanical mixture of active ingredients and excipients since its ingredients do not interact with each other.

2. The production of nasal gel with dry extract of licorice root and essential oils of Siberian pine and eucalyptus at temperatures taken in the process of carbomer gel (room temperature) does not lead to the destruction of the components of investigated dosage form.

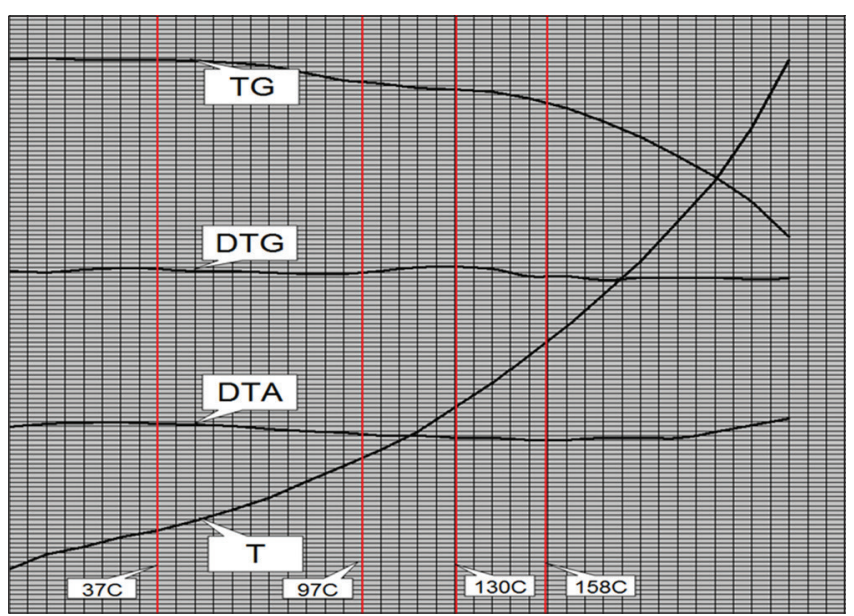

Fig. 1: Derivatogram of dry extract of licorice root

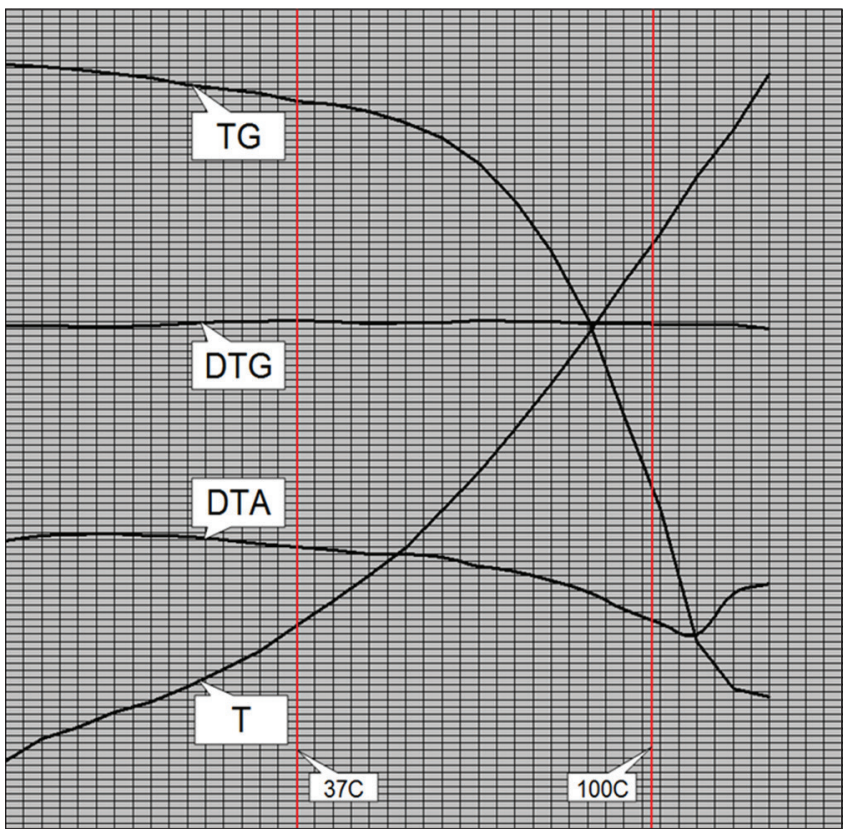

Fig. 2: Derivatogram of investigated nasal gel 


\section{AUTHORS' CONTRIBUTIONS}

All authors have made substantial contributions to the work reported in the manuscript.

\section{CONFLICTS OF INTEREST}

All the authors hereby declare that there are no conflicts of interest.

\section{REFERENCES}

1. Mirmoezzi MS, Yazdi MS, Gholami O. Comparative study on the efficacy of mometasone and fluticasone nasal sprays for treatment of allergic rhinitis. Int J Pharm Pharm Sci 2017;9:211-4.

2. Chowdhury MA, Rabbani SM, Yasmeen N, Malakar M. Rhinitis: Present perspective. Bangladesh J Otorhinolaryngol 2010;16:44-7.

3. Williams DC, Edney G, Maiden B, Smith PK. Recognition of allergic conjunctivitis in patients with allergic rhinitis. World Allergy Organ J $2013 ; 6: 331-7$
4. Shah A, Pawankar R. Allergic rhinitis and co-morbid asthma: Perspective from India-ARIA Asia-pacific workshop report. Asian Pac J Allergy Immunol 2009;27:71-7.

5. Demoly P, Calderon MA, Casale T, Scadding G, Annesi-Maesano I, Braun JJ, et al. Assessment of disease control in allergic rhinitis. Clin Transl Allergy 2013;3:7

6. Kennedy J. Self-Care of Rhinitis. Self Care 2011;2:55-9.

7. Dhananjaya BL. Drugs from nature: plants as an important source of pharmaceutically important metabolites. Int J Pharm Pharm Sci 2015;7:1.

8. Angiera E, Willingtonb J, Scaddingc G, Holmes S, Walker S; British Society for Allergy and Clinical Immunology (BSACI) Standards of Care Committee. Management of allergic and non-allergic rhinitis: A primary care summary of the BSACI guideline. Prim Care Respir J 2010;19:217-22

9. Finch CA. Chemistry and Technology of Water-Soluble Polymers. New York: Springer Science \& Business Media; 2013.

10. Jacoby R, Pernenkil L, Sabad A, Heim M. Advanced Biopharmaceutical Manufacturing: An Evolution Underway. Oakland, CA: Deloitte; 2015. 